\title{
Gene Transfer Therapy for Neurodevelopmental Disorders
}

\author{
Can Ozlu $^{a}$ Rachel M. Bailey ${ }^{a, b}$ Sarah Sinnett ${ }^{a, c}$ Kimberly D. Goodspeed ${ }^{a}$ \\ ${ }^{a}$ Department of Pediatrics, University of Texas Southwestern Medical Center, Dallas, TX, USA; ${ }^{b}$ Center for \\ Alzheimer's and Neurodegenerative Diseases, University of Texas Southwestern Medical Center, Dallas, TX, USA; \\ 'Eugene McDermott Center for Human Growth and Development, University of Texas Southwestern Medical \\ Center, Dallas, TX, USA
}

\section{Keywords}

Neurodevelopmental disorder - Gene therapy · Fragile X syndrome Rett syndrome - Angelman syndrome .

SLC13A5 - SLC6A1

\section{Abstract}

Neurodevelopmental disorders (NDDs) include a broad spectrum of disorders that disrupt normal brain development. Though some NDDs are caused by acquired insults (i.e., toxic or infectious encephalopathy) or may be cryptogenic, many NDDs are caused by variants in a single gene or groups of genes that disrupt neuronal development or function. In this review, we will focus on those NDDs with a genetic etiology. The exact mechanism, timing, and progression of the molecular pathology are seldom well known; however, the abnormalities in development typically manifest in similar patterns such as delays or regression in motor function, social skills, and language or cognitive abilities. Severity of impairment can vary widely. At present, only symptomatic treatments are available to manage seizures and behavioral problems commonly seen in NDDs. In recent years, there has been a rapid expansion of research into gene therapy using adeno-associated viruses (AAVs). Using AAVs as vectors to replace the non- or dysfunctional gene in vivo is a relatively simple model which has created an unprecedented opportunity for the future of NDD treatment. Advances in this field are of paramount importance as NDDs lead to a massive lifelong burden of disease on the affected individuals and families. In this article, we review the unique advantages and challenges of AAV gene therapies. We then look at potential applications of gene therapy for 3 of the more common NDDs (Rett syndrome, fragile X syndrome, and Angelman syndrome), as well as 2 less common NDDs (SLC13A5 deficiency disorder and SLC6A1-related disorder). We will review the available natural history of each disease and current state of preclinical studies including a discussion on the application of AAV gene therapies for each disease.

(c) 2021 S. Karger AG, Basel

\section{Introduction}

The United States' National Health Interview Survey (NHIS) has collected data on the prevalence of developmental disabilities since 1997 and demonstrated a rise in prevalence from $13.9 \%$ (1997-2008) to $16.93 \%$ (20092017) for any developmental delay among children ages karger@karger.com www.karger.com/dne (c) 2021 S. Karger AG, Base

Karger
Correspondence to:

Kimberly D. Goodspeed, kimberly.goodspeed@utsouthwestern.edu 
3-17 years [1]. This constitutes an increase of $9.5 \%$ for any developmental delay, and a notable rise in the rates of autism spectrum disorder (ASD) and intellectual disability (ID) of 122.3 and $25.8 \%$, respectively, and means that 1 in 6 children in the United States have a developmental disability [1]. Because some neurodevelopmental disorders (NDDs) are linked to genetic variants, current guidelines recommend that children diagnosed with ASD or global developmental delay undergo an evaluation for genetic etiology in addition to receiving general developmental interventions $[2,3]$. Although $90 \%$ of rare diseases do not currently have an approved treatment, development of precision therapies for each of these rare disorders are on the rise $[4,5]$. There are several challenges to precision therapy programs in NDDs including successfully modeling the disorder in animals, timing the intervention appropriately along the developmental trajectory, and selecting the proper patient population and clinical outcome measures $[6,7]$. The failed clinical trials of novel and repurposed compounds in fragile X syndrome (FXS) exemplify these challenges [7]. These failed trials also shed light on important considerations for rare disease clinical and translational research such as improving the translatability of preclinical studies and exploring alternative designs for pediatric clinical trials in NDDs [7]. Despite these challenges, 1 avenue of exploration is viralmediated gene transfer for monogenic neurodevelopmental disorder.

\section{Brief History of Virus-Mediated Gene Therapy}

There has been much progress since the conception of the ground-breaking idea of using viruses as vectors for gene therapy in the twentieth century [8]. The small (20$25 \mathrm{~nm}$ ), nonenveloped single-stranded DNA virus called adeno-associated virus (AAV), initially discovered in the 1960 s, has become a potent delivery tool widely researched by groups across the world [9]. To date, $3 \mathrm{AAV}$ based gene therapy products for inherited diseases (i.e., alipogene tiparvovec [Glybera], voretigene neparvovecrzyl [Luxturna], and onasemnogene abeparvovec-xioi [Zolgensma]) received marketing approval from the European Medicines Agency and the American Food and Drug Administration and hundreds more are under clinical investigation [10-12]. In 2012, Glybera was approved by the European Medicines Agency to treat lipoprotein lipase deficiency, in 2017 Luxturna was approved in the United States for a rare inherited retinal dystrophy, Leber congenital amaurosis, and most recently in 2019 Zolgens- ma was approved in the United States for spinal muscular atrophy.

AAVs have several advantages making them attractive as gene therapy vectors, especially for CNS diseases, tempered by some caveats. First, there are naturally occurring serotypes of AAV that have diverse tissue and cellular tropisms. One of these serotypes, AAV9, is the current gold standard for CNS gene therapy, which can cross the blood-brain barrier with systemic administration and has a tropism for neurons and neuroglia [13]. The efficacy of CNS transduction can be increased further by intrathecal vector delivery directly into the cerebrospinal fluid, thereby reducing exposure of the peripheral tissues to the viral vector, most notably the liver which is highly transduced by AAV9 $[14,15]$. The wild-type AAV genome consists of inverted terminal repeats flanking the rep and cap. The rep gene encodes replication proteins (Rep78, Rep68, Rep52, and Rep40) from a single open reading frame and from 2 open reading frames in the cap gene capsid proteins (VP1, VP2 and VP3) and the assembly-activating protein are encoded. A recombinant AAV used for gene therapy contains only the viral inverted terminal repeats flanking the desired gene expression cassette (transgene), which traditionally consists of a promoter, gene of interest, polyA tail, and optional regulatory elements. The transgenes can circularize or concatemerize within the cells, forming episomes with minimal integration into the host-cell genome [16-19]. This offers a unique safety advantage over retroviruses and lentiviruses where integration into host genome causes risk of oncogenicity, as was unfortunately reported in earlier clinical trials with retroviruses [20]. The episomes will persist in nondividing cell populations (e.g., neurons) for long periods of time while being diluted and lost in replicating cells. The persistence of the transduced gene product in the nondividing cells of CNS may make AAV the ideal choice for simple gene replacement models.

Current challenges to AAV gene therapy include the host immune response and limited packaging capacity. First, both the vector DNA and surrounding protein capsid of AAVs can induce an unwanted innate and adaptive immune response $[21,22]$, while the transgene product can also be immunogenic in patients with null mutations [23]. To counter this challenge, it may be possible to bioengineer the viral capsid for less immunogenicity or use the more pragmatic approach of directed evolution, making a library of AAVs with diverse capsids through errorprone PCR and/or shuffling genome fragments and selecting for the most resistant variants [24, 25]. Additionally, emerging data from clinical and preclinical studies 
support that the $\mathrm{CpG}$ content in the vector genome greatly increases vector immunogenicity $[26,27]$ and a CpGdepleted genome may help counter this [28]. Currently, most gene therapy programs utilize immunosuppression of the participant to blunt the potentially deleterious effects of the immune response. The AAV genome size limits the gene product that can be packaged to less than 4.4 $\mathrm{kb}$ in single stranded and less than $2.2 \mathrm{~kb}$ in the more efficacious self-complementary packaging approach. Based on these size limitations, single-stranded and self-complementary AAVs can be used for 95 and $66 \%$ of the coding sequences in the human genome, respectively [29]. Although most disorders will thus be able to be covered by these models, application for other diseases like $\mathrm{Du}$ chenne's muscular dystrophy and delivery of more complex systems (e.g., CRISPR-Cas9 and addition of regulatory elements) are hindered by the size limit. The size limit may be expanded in the future by dual vector systems $[30,31]$ or worked around by transducing only the functional domain. Due to its versatility and expanding number of clinical trials with AAV gene therapies, there is great interest in improving various aspects of the vector, such as the capsid $[32,33]$, the transgene product [34], and the manufacturing process [32].

\section{Rett Syndrome}

Rett syndrome (RTT; OMIM \#312750) is an X-linked neurodevelopmental disorder that affects females. Though RTT remains a clinical diagnosis, in the classical form a loss of function variants of $M E C P 2$ is identified. Girls have a period of normal development that is followed by arrest and then regression of developmental skills in the second year of life, especially in communication and fine motor skills [35]. Other hallmark features include microcephaly, seizures, ID, and stereotypical movements of hands [36]. Breathing abnormalities manifesting as apnea, forced or irregular breathing with exaggerated or inadequate autonomic responses are frequently seen, and sudden death presumed to be related to autonomic dysfunction is a serious concern [37]. There can be overlap between the initial presentation of milder cases of RTT and ASD [38]. Recent data from the National Institutes of Health Rett and Rett-Related Disorders Natural History Study (RNHS) has revealed interesting findings about the clinical features. Internalizing behaviors (e.g., anxiety, depression, abrupt mood changes, and social withdrawal) are universal among RTT patients, whereas externalizing behaviors (e.g., aggression, self- abuse, inconsolable crying, screaming, and impulsivity) are more commonly seen in younger, less severely affected individuals [39]. Regression of skills is much more common in RTT compared to the "RTT-like disorders"; CDKL5, FOXG1, and MECP2 duplication disorder [40]. In some girls, early milestones are delayed or absent and the level of skill acquisition predicts future clinical severity. Furthermore, skills in gross motor and receptive communication domains are retained better than fine motor or expressive language domains [41].

RTT is caused by inactivating mutations in the transcription regulator methyl CpG-binding protein 2 (MeCP2). The prevalence is estimated to be 1 in 10,000 young girls [42]. It is inherited in an X-linked dominant pattern, most cases are female heterozygotes with somatic mosaicism due to X chromosome inactivation. Males are much more severely affected as they have $1 \mathrm{X}$ chromosome. Although normal function of $\mathrm{MeCP} 2$ is unclear, we know through mice studies that the loss of function causes potentially reversible synaptic changes rather than neuronal death or axonal degeneration $[43,44]$. This is an encouraging finding for gene therapy approaches and is consistent with reversibility of disease seen in mouse models [45].

A crucial consideration for RTT gene therapy, well known from mouse models and $\mathrm{MeCP} 2$ duplication disorder patients, is that MECP2 overexpression can cause neurological dysfunction $[45,46]$. Additionally, in a mouse model, intravenous delivery of a first-generation AAV9-mediated gene therapy was shown to cause high expression levels in the heart and liver, leading to acute liver damage [47]. In the same study, transduction efficiency was low in adolescent mice (less than $5 \%$ in several brain regions) [47]. More recent preclinical studies of AAV9 gene therapy RTT mice have mitigated toxicity by utilizing intracerebrospinal fluid delivery and using regulatory elements that achieve lower expression levels (e.g., a MECP2 promoter variant and miRNA binding sites) $[48,49]$. These studies have demonstrated that in preclinical models, safer levels of exogenous MeCP2 expression can be achieved with AAV9 gene therapy, improving survival across studies and achieving variable neurological improvements. Though promising, successful preclinical gene therapy studies in newborn mice are considered a proof-of-concept study and are not readily translatable to human patients. Although extremely optimistic, positive outcomes in human RTT may not be possible to infer without clinical data, especially in language and behavior (e.g., anxiety and depression) domains less well studied in these models. 


\section{Fragile X Syndrome}

FXS (OMIM \#300264) is an X-linked genetic disorder characterized clinically by ID, distinct facial features (long narrow face, prominent ears and jaw), and macroorchidism [50, 51]. FXS is also commonly associated with drug-responsive epilepsy [52]. FXS is classically described in male patients who present with pervasive delays in all domains from infancy [53]. In a 20-year followup study from Finland, FXS patients were shy but socially interactive and had improvement of skills until 25 years old and worsening motor skills after age 50 [54]. FXS can present with autistic traits such as impaired communication, stereotyped behaviors, and sensory hypersensitivity $[55,56]$. In a recent study, using the DSM$\mathrm{V}$ criteria for ASD, $50 \%$ of male and $20 \%$ of female FXS patients were diagnosed with ASD [56]. ADHD, anxiety, and depression are common neuropsychiatric comorbidities for FXS patients and add to the disease burden $[57,58]$.

FXS is typically caused by unstable expansion of a CGG trinucleotide repeat in the $5^{\prime}$ untranslated region of the FMR1 gene on $\mathrm{X}$ chromosome, though deletions and sequence variants have been reported $[59,60]$. Greater than 200 CGG repeats are diagnostic for FXS. It is inherited in an X-linked dominant pattern, and prevalence is reported to be approximately 1 in 4,000-7,000 males and 1 in 6,000-11,000 females [61,62], making it the most frequent monogenic cause of ID. Individuals with a normal number of repeats (5-55 repeats) as well as intermediate expansions (up to 200 repeats) may be diagnosed with fragile $\mathrm{X}$-associated tremor/ataxia syndrome or premature ovarian insufficiency in females [63]. In FXS patients, the CGG repeat expansion leads to hypermethylation of the promoter and CGG repeat region, resulting in transcriptional silencing [64]. Furthermore, the transcribed repeat in the FMR1 mRNA makes translation inefficient [65] and hybridizes with the complementary region in the DNA, inducing silencing of the gene [66]. Due to heterogeneity in the size of repeat region, level of methylation, and possible other factors, FMRP levels can be variable between fragile $\mathrm{X}$-associated tremor/ataxia syndrome/FXS patients [67]. FMRP is a pleiotropic protein crucial in CNS development $[68,69]$, believed to regulate expression of many proteins, albeit its exact function is unknown.

As with many NDDs, treatment of FXS patients consists of symptomatic management with off-label use of many psychiatric medications as well as antiseizure medications for seizures. Although there have been many clinical trials in recent years, none have shown clear benefit. Novel drugs, such as mGluR5 antagonists and GA$\mathrm{BAb}$ agonists, demonstrated solid preclinical findings but were unable to show convincing efficacy in early phase clinical trials [7]. The failure of these clinical trials highlighted some of the shortcomings of the models for translational research in FXS and NDDs in general [7, 70, 71]. In FXS, the trinucleotide repeat expansion leads to gene silencing in humans, which is difficult to simulate in a mouse model. Instead, the FXS mouse model most commonly used in preclinical studies has a full deletion of the FMR1 gene causing complete lack of FMRP [72] which may be pathologically divergent from the human disease. Furthermore, even though these mice displayed molecular defects and behavioral patterns seemingly consistent with FXS, some aspects of the phenotypes are difficult to reproduce; thus, correction of a biological phenotype in the animal model may not always be a reliable predictor of clinical success [73-75]. Generating a preclinical model highly predictive for clinical outcome is probably made even more challenging by the gaps in knowledge of the function of FMRP.

Despite existing limitations of the mouse models, preclinical studies of FXS AAV gene therapy are showing promise. First, using an intracerebroventricular injection of AAV9/FMRP, stable levels of FMRP expression were seen in periventricular regions of the brain. This rescued the social and behavioral symptoms but did not affect motor hyperactivity or seizures [76]. In subsequent studies, AAV9/FMRP yielded expression levels of FMRP which were $35-115 \%$ of wild-type levels and partially rescued the anxiety and motor behavior phenotypes in addition to correcting the expression levels of 2 of the protein's substrates; PSD-95 and MeCP2 to wild-type levels. Furthermore, they demonstrated that modest overexpression of FMRP was safe, while excessive (over 2-fold wild-type levels) overexpression was associated with worsening motor hyperactivity [77]. One major challenge is achieving sufficient biodistribution of transduced neurons across brain regions farther from the ventricles [76]. Overall, these studies contributed vital information for the goal of treating FXS with gene therapy [78].

\section{Angelman Syndrome}

Angelman syndrome (AS; OMIM \#105830) is a severe genetic neurodevelopmental disorder characterized by global developmental delay, epilepsy, ID, ataxia, hypotonia with hyperreflexia, microcephaly, and a characteris- 
tic happy disposition with bursts of laughter [79]. Most patients have comorbid epilepsy with a variety of seizure types and a signature electroencephalogram (EEG) pattern of diffuse, high-amplitude, slow rhythmic waves [80]. Infants with AS routinely have delayed myelination for their age on brain MRIs [81]. The severe developmental delay and clinical symptoms have substantial overlap with other NDDs such as 15q11-q13 duplication syndrome (OMIM \#608636). Nonetheless, the unique behavioral phenotype of constant smiling, happy grimacing, giggling, paroxysms of laughter beginning in early infancy, and hypermotoric activity with jerky, tremulous, or ataxic movements point to the diagnosis in children with AS [82]. Severe limitations of activities of daily living, challenging behaviors, persistence of seizures, and diminished mobility all continue into adulthood, yielding a significant disease burden across the lifespan [83].

AS is caused by a lack of expression of the maternal copy of the ubiquitin-protein ligase E3A gene (UBE3A) [84]. Normally, the UBE3A gene is imprinted. This means it is expressed in a parent-of-origin specific manner such that the paternal copy is silenced in the brain while the maternal copy is expressed $[85,86]$. Thus, individuals develop AS when the maternal copy is lost through 1 of 4 mechanisms: deletions on 15q11-q13 including UBE3A ( $70 \%$ of cases), molecular variants ( 10\%), imprinting defects $(\sim 10 \%)$, and paternal uniparental disomy $(\sim 10 \%)$ [84]. Some individuals have a milder phenotype when the genetic variant results in a modified but functional UBE3A protein [79] or when there is a mosaic pattern of imprinting defects [87]. Patients with uniparental disomy have 2 of the silenced paternal copies likely due to a maternal nondisjunction event and paternal chromosome duplication [84]. Individuals with a deletion, the most common genotype, are typically the most severely affected [88]. These genotype-phenotype relationships may indicate that additional genes are contributing to the pathogenesis via loss of adjacent genes in the deletion subtype and overexpression of maternally silenced genes in the uniparental disomy subtype [88]. The most commonly used AS mouse model harbors a frameshift variant in $U B E 3 A$ and recapitulates core aspects of the human disease including motor impairments, behavioral problems, vocalization abnormalities, and seizures $[89,90]$. Intrahippocampal injection of AAV9/UBE3A partially rescued learning and long-term potentiation in the AS mice but showed no effect on motor symptoms [91]. In a CreLox inducible UBE3A mouse model, motor symptoms, long-term potentiation, and seizures were improved by reactivation of the gene in the newborn period, but behavioral symptoms were unchanged [92], argued to be due to only partially restored expression levels [90, 92]. One intriguing approach is un-silencing the functional but dormant paternal copy in the CNS [93], which was first shown to be possible by intracerebroventricular administration of the topoisomerase inhibitor topotecan, although off-target effects and overall toxicity would likely prevent the drug from being directly used [94]. Another promising approach is to activate the dormant paternal copy using an antisense oligonucleotide which resulted in partial rescue of UBE3A expression for 4 months and improvement in memory (cognitive) but no other domain symptoms in a preclinical study $[95,96]$. GTX-102, an antisense oligonucleotide based on the aforementioned mechanism is currently in clinical trial stage [97]. Recently, another group has demonstrated that it is possible to use an AAV-delivered CRISPR Cas9 gene editing system to activate the paternal copy, partially restoring UBE3A levels and improving behavior phenotype in an AS mouse model [98].

The challenges to be addressed in developing an effective gene therapy for AS stem mainly from the genetic complexity with different subtypes, possible involvement of multiple genes in the most common and most severe subtype (maternal copy deletion) and the perhaps narrow physiologic expression range of UBE3A [99], while the existence of the silenced paternal copy of the gene provides unique avenues for exploration.

\section{SLC13A5 Deficiency Disorder}

SLC13A5 deficiency disorder (SDD; citrate transporter disorder, EIEE 25, OMIM\# 608305) is an early infantile epileptic encephalopathy that presents with seizure onset within the first week of life [100-102]. SDD is caused by biallelic loss of function variants in the SLC13A5 gene, which encodes a sodium-dependent citrate transporter that is responsible for uptake of citrate into the cell [103]. This leads to relative depletion of citrate intracellularly and elevated citrate levels outside the cell [104]. It is highly expressed in the brain, testes, teeth, and liver [105].

Though the exact pathophysiology of how loss of function variants lead to the clinical phenotype is not fully understood, it is hypothesized that intracellular depletion of citrate may disrupt cellular metabolism, especially in neurons [104]. Cytoplasmic citrate serves as a carbon source for neurotransmitters including glutamate and GABA [106]. It is therefore possible that cytoplasmic 
depletion of citrate impedes the synthesis of GABA and could contribute to the neurodevelopmental and epileptic manifestations of the disorder [107]. Interestingly, stiripentol was shown to reduce seizure burden in 3 patients with SDD, possibly through enhancement of GABA neurotransmission [108]. This relative energy imbalance may also increase seizure susceptibility in patients [109]. Additionally, elevated extracellular citrate levels may increase seizure activity by chelating zinc and thereby potentiating activity at synaptic NMDA receptors [107].

Patients with SDD almost invariably present with convulsive seizures within the first week of life and often progress to drug-resistant epilepsy that persist throughout the lifespan $[100-102,104,110]$. Most seizures are convulsive (e.g., hemiclonic, myoclonic, and generalized tonic clonic), but some patients are reported to have subclinical seizure, nonconvulsive status epilepticus, and absence or atypical absence seizures [100, 101, 104, 111]. In vivo experiments in Slc13a5 $5^{-/-}$mice recapitulated this aspect of the disease, albeit to a greatly reduced extent, as compared to patients and showed a gender difference with female mice having a more severe susceptibility to seizures [112]. There may be a worsening of seizures with fever in childhood; however, as some patients age, they experience a reduction in seizure severity [110]. Detailed data on developmental abilities are limited; however, patients typically have severe motor impairment and marked deficits in cognitive and expressive language skills, though receptive language is estimated to be stronger $[100,110]$. A characteristic pattern of punctate white matter lesions that progressed to gliosis were identified in a small cohort of SDD patients but are not of clear clinical significance [113]. A review of EEGs of patients with SDD reveals an evolution from status epilepticus with a discontinuous background in the neonatal period, when seizures are at their peak, that improve to normalization of the background with multifocal sharp waves later in life when seizures diminish [111]. Even in patients with a significant seizure burden, the background EEG was well organized and not suggestive of an epileptic encephalopathy [100]. Individuals commonly have abnormalities of the tooth enamel as well [114]. Though there is limited data on the expected lifespan of patients with SDD, a recent report of siblings in their fifties (56-year-old sister and 54-year-old brother) suggests that while the disorder is extremely disabling, patients can live well into adulthood [115].

Given that the SLC13A5 coding sequence is $\sim 1.7 \mathrm{~kb}$ and mutations lead to a loss of function, gene replace- ment therapy using an AAV vector is a viable approach for treating patients. Our group has developed an AAV/ SLC13A5 treatment, and preclinical studies are ongoing in $S l c 13 a 5^{-1-}$ mice to test the safety and efficacy of this approach (in preparation, Rachel M. Bailey). The prolonged survival of SDD patients together with an organized background EEG suggest there could be a large therapeutic window in which a virus-mediated gene transfer application may be successful.

\section{SLC6A1-Related Disorder}

SLC6A1-related disorder (SRD; OMIM\# 137165) is complex neurodevelopmental disorder that is emerging as a common cause of developmental disability and epilepsy. It was first described in 2015 among a cohort of patients with Doose syndrome [116], but the phenotype continues to expand as more patients are identified [117]. A recent compilation of 116 patients with SRD identified the core features of the disorder to include epilepsy (91\%), developmental delay or cognitive impairment (82\%), and autistic traits (23\%) [118]. The prominent epilepsy syndrome was epilepsy with myoclonic-atonic seizure (24\%), and many patients also had absence or atypical absence seizure (72\%). On EEG, many patients have generalized epileptiform discharges, notably in the frequency of $3 \mathrm{~Hz}$, as well as generalized background slowing $[118,119]$.

SRD is caused by haploinsufficiency of the SLC6A1 gene on chromosome 3 . The gene contains 15 exons and encodes the GABA transporter type-1, which is responsible for reuptake of GABA from the synaptic cleft into the presynaptic cleft [120]. In humans, SLC6A1 is predominantly expressed in the central nervous system, especially in the frontal cortex [121], in both neurons and glia [122]. GABA transporter type-1 expression is expressed within GABAergic neurons from an early stage of neuronal development, although the GABAergic system continues to develop through adolescence [123, 124]. Though studies to fully understand the pathophysiology of SRD are underway, GABA homeostasis appears to be critical to brain development in humans. Interestingly, the heterozygous knockout mouse model of SRD is phenotypically normal even though there is a deficiency of GABA-reuptake capacity $[125,126]$, while the homozygous knockout mice recapitulate the human disease more closely with motor impairments (e.g., tremor, gait abnormalities, and weakness) and anxiety on behavioral assays [125]. 
Like many other NDDs, treatment is currently focused on managing symptoms of the disease including antiseizure medication, supportive developmental therapies, and medications to decrease the burden of symptoms such as behavioral problems, sleep problems, or gastrointestinal distress. Antiseizure medications that are broad spectrum and commonly used in generalized epilepsy syndromes such as valproic acid or benzodiazepines appear to be effective in SRD as well [119]. However, several targeted therapies are in development. Because SLC6A1 is small enough to package in an AAV9 vector [127], is caused by loss-of-function variants [128] and has a targetable protein product [129], it is a viable candidate for targeted therapy, including virus-mediated gene transfer therapy. Understanding the full spectrum of the human clinical phenotype and improved understanding of the underlying pathophysiology in terms of the downstream effects of GABA homeostasis are critical to successful clinical and translational precision therapy programs for SRD.

\section{Conclusion}

Genetically linked NDDs, albeit rare individually, are a common group of conditions when combined, placing an enormous burden on families worldwide. Nevertheless, current standards of care are limited to supportive developmental therapies and symptomatic management of comorbidities. Ergo, there is a great need for novel treatments. A variety of alternative approaches ranging from dietary supplements [130] to acting on potential downstream targets [131] are beyond the scope of this review but may show clinical benefit in the future for NDDs and hopefully be used individually or in combination with gene therapies.

Reestablishing physiologic expression of the gene whose function is lost during early brain development is an alluring pragmatic approach. AAV-mediated gene therapy is on the path to becoming a safe and effective method for this purpose. However, any such novel therapy must prove itself in preclinical and clinical experiments, and there are challenges to be confronted, such as (i) improving CNS transduction efficiency while ensuring specificity; (ii) mitigating the immune response to AAV administration; and (iii) addressing packaging capacity issues when necessary. Furthermore, preclinical modeling of NDDs bears special difficulties. There are limitations in recapitulating the human behavioral phenotypes in animal models as well as vast differences in chronology of brain development between mice and humans. An important question regarding developmental disorders is whether there is a defined therapeutic window in which we must intervene to see clinical benefit. In disorders like RTT, the mouse phenotype was rescued in the postnatal period, suggesting that there was a problem with connectivity rather than irreparable structural defects. In fact, in many NDDs, conventional brain imaging is unrevealing; however, functional connectivity may demonstrate deficits [132]. Findings from EEG studies support the dysfunctional connectivity hypothesis in identification of aberrant signaling on event-related potentials and ongoing work in quantitative EEG analyses [133-135]. These studies highlight an important consideration in clinical and translational research programs for the NDDs.

Finally, to evaluate the efficacy of a novel treatment, we must understand the full phenotypic spectrum of each disorder, define the natural clinical progression over the lifetime, and identify appropriate clinical outcome measures and objective biomarkers that can capture the salient aspects of the disease and how they change over time. As precision therapies get closer to the clinic for NDDs, natural history studies are evolving into clinical trial readiness programs and sometimes serve as the historical controls or comparator arm for the clinical trials. For our well-known disorders, much of the work is focused on improving the precision of biomarkers of each disease, while the more recently described disorders are also striving to understand the epidemiology and phenotypic spectrum of each disorder. Regardless of the disorder in question, success of a clinical trial hinges on the selection of the appropriate patient population and inclusion of clinical outcome measures that are adequately sensitive to measure clinically meaningful changes in how the patient performs in their daily lives. Aligning pivotal preclinical studies with observational studies of human subjects may be one way to improve efficiency and narrow the translational gap from bench to bedside.

\section{Acknowledgements}

The authors would like to acknowledge the support of the team of investigators and support staff within the UTSW gene therapy program, especially the leadership and pioneering vision of Berge Minassian, MD, and Steven Gray, PhD, without whom, the program would not exist. The authors would also like to acknowledge the patients and their families who are affected by the NDDs discussed in this review. It is through their support and insights as the true experts in these disorders that this innovative work can flourish. 


\section{Conflict of Interest Statement}

C.O. does not have any relevant financial disclosures. K.G. has received consultative fees from Neurogene Inc., for work unrelated to that which was reviewed here. UT Southwestern holds equity in Taysha Gene Therapies. R.M.B. has sponsored research agreements with Taysha Gene Therapies, which is a licensee of UTSW technology. R.M.B. is an inventor on patents that have been licensed to various biopharmaceutical companies and for which she may receive payments. S.S. has sponsored research agreements with Taysha Gene Therapies, which is a licensee of UTSW technology. S.S. has received royalties for IP licensed to Abeona Therapeutics, but that IP is not discussed herein.

\section{Funding Sources}

There is no funding source for this review article.

\section{Author Contributions}

C.O. and K.G. made significant contributions to drafting the review manuscript. R.M.B. and S.S. contributed significant revisions to the draft. All authors provided final approval of the manuscript.

\section{References}

1 Zablotsky B, Black LI, Maenner MJ, Schieve LA, Danielson ML, Bitsko RH, et al. Prevalence and trends of developmental disabilities among children in the United States: 20092017. Pediatrics. 2019;144(4).

2 Hyman SL, Levy SE, Myers SM. Council on children with disabilities, section on developmental and behavioral pediatrics. Identification, evaluation, and management of children with autism spectrum disorder. Pediatrics. 2020;145(1).

3 Schaefer GB, Mendelsohn NJ; Professional Practice and Guidelines Committee. Clinical genetics evaluation in identifying the etiology of autism spectrum disorders: 2013 guideline revisions. Genet Med. 2013 May;15(5):399407.

4 Malinowski J, Miller DT, Demmer L, Gannon J, Pereira EM, Schroeder MC, et al. Systematic evidence-based review: outcomes from exome and genome sequencing for pediatric patients with congenital anomalies or intellectual disability. Genet Med. 2020 Jun;22(6): 986-1004.

5 Tabor HK, Goldenberg A. What precision medicine can learn from rare genetic disease research and translation. AMA J Ethics. 2018 01;20(9):E834-840.

6 Loth E, Murphy DG, Spooren W. Defining precision medicine approaches to autism spectrum disorders: concepts and challenges. Front Psychiatry. 2016;7:188.

7 Berry-Kravis EM, Lindemann L, Jønch AE, Apostol G, Bear MF, Carpenter RL, et al. Drug development for neurodevelopmental disorders: lessons learned from fragile X syndrome. Nat Rev Drug Discov. 2018;17(4):280-99.

8 Friedmann T, Roblin R. Gene therapy for human genetic disease? Science. 1972 Mar 3; 175(4025):949-55.

9 Wu Z, Asokan A, Samulski RJ. Adeno-associated virus serotypes: vector toolkit for human gene therapy. Mol Ther. 2006 Sep;14(3):31627.

10 Ylä-Herttuala S. Endgame: glybera finally recommended for approval as the first gene therapy drug in the European union. Mol Ther. 2012 Oct;20(10):1831-2.
11 FDA approves hereditary blindness gene therapy. Nat Biotechnol. 2018 10;36(1):6.

12 Hoy SM. Onasemnogene abeparvovec: first global approval. Drugs. 2019 Jul;79(11): 1255-62.

13 Foust KD, Kaspar BK. Over the barrier and through the blood: to CNS delivery we go. Cell Cycle. 2009 Dec 15;8(24):4017-8.

14 Samaranch L, Salegio EA, San Sebastian W, Kells AP, Foust KD, Bringas JR, et al. Adenoassociated virus serotype 9 transduction in the central nervous system of nonhuman primates. Hum Gene Ther. 2012 Apr;23(4):382-9.

15 Gray SJ, Matagne V, Bachaboina L, Yadav S, Ojeda SR, Samulski RJ. Preclinical differences of intravascular AAV9 delivery to neurons and glia: a comparative study of adult mice and nonhuman primates. Mol Ther. 2011 Jun; 19(6):1058-69.

16 Choi VW, McCarty DM, Samulski RJ. Host cell DNA repair pathways in adeno-associated viral genome processing. J Virol. 2006 Nov 1;80(21):10346-56.

17 Smith RH. Adeno-associated virus integration: virus versus vector. Gene Ther. 2008; 15(11):817-22.

18 Valdmanis PN, Lisowski L, Kay MA. rAAVmediated tumorigenesis: still unresolved after an AAV assault. Mol Ther. 2012;20(11):20147.

19 Li H, Malani N, Hamilton SR, Schlachterman A, Bussadori G, Edmonson SE, et al. Assessing the potential for AAV vector genotoxicity in a murine model. Blood. 2011;117(12): 3311-9.

20 Hacein-Bey-Abina S, Garrigue A, Wang GP, Soulier J, Lim A, Morillon E, et al. Insertional oncogenesis in 4 patients after retrovirus-mediated gene therapy of SCID-X1. J Clin Invest. 2008 Sep;118(9):3132-42.

21 Zhu J, Huang X, Yang Y. The TLR9-MyD88 pathway is critical for adaptive immune responses to adeno-associated virus gene therapy vectors in mice. J Clin Invest. 2009 Aug; 119(8):2388-98.

22 Hösel M, Broxtermann M, Janicki H, Esser K, Arzberger S, Hartmann P, et al. Toll-like receptor 2-mediated innate immune response in human nonparenchymal liver cells toward adeno-associated viral vectors. Hepatology. 2012 Jan;55(1):287-97.

23 Mendell JR, Campbell K, Rodino-Klapac L Sahenk Z, Shilling C, Lewis S, et al. Dystrophin immunity in Duchenne's muscular dystrophy. N Engl J Med. 2010 Oct 7;363(15): 1429-37.

24 Rabinowitz J, Chan YK, Samulski RJ. Adenoassociated virus (AAV) versus immune response. Viruses. 2019;11(2): 102

25 Li W, Asokan A, Wu Z, Van Dyke T, DiPrimio N, Johnson JS, et al. Engineering and selection of shuffled AAV genomes: a new strategy for producing targeted biological nanoparticles. Mol Ther. 2008 Jul;16(7):1252-60.

26 Xiang Z, Kurupati RK, Li Y, Kuranda K, Zhou $\mathrm{X}$, Mingozzi F, et al. The effect of CpG sequences on capsid-specific CD8+ T cell responses to AAV vector gene transfer. Mol Ther. 2020;28(3):771-83.

27 Ashley SN, Somanathan S, Giles AR, Wilson JM. TLR9 signaling mediates adaptive immunity following systemic AAV gene therapy. Cell Immunol. 2019;346:103997.

28 Faust SM, Bell P, Cutler BJ, Ashley SN, Zhu Y, Rabinowitz JE, et al. CpG-depleted adeno-associated virus vectors evade immune detection. J Clin Invest. $2013 \mathrm{Jul} ; 123(7): 2994-$ 3001 .

29 Lykken EA, Shyng C, Edwards RJ, Rozenberg A, Gray SJ. Recent progress and considerations for AAV gene therapies targeting the central nervous system. J Neurodev Disord. 2018 18;10(1): 16

30 Duan D, Yue Y, Engelhardt JF. Expanding AAV packaging capacity with trans-splicing or overlapping vectors: a quantitative comparison. Mol Ther. 2001 Oct;4(4):383-91.

31 Ghosh A, Yue Y, Lai Y, Duan D. A hybrid vector system expands adeno-associated viral vector packaging capacity in a transgene-independent manner. Mol Ther. 2008 Jan;16(1): 124-30.

32 Naso MF, Tomkowicz B, Perry WL, Stroh WR. Adeno-associated virus (AAV) as a vector for gene therapy. BioDrugs. 2017 Aug; 31(4):317-34. 
33 Eichhoff AM, Börner K, Albrecht B, Schäfer W, Baum N, Haag F, et al. Nanobody-enhanced targeting of AAV gene therapy vectors. Mol Ther Methods Clin Dev. 2019 Dec 13;15:211-20.

34 Powell SK, Rivera-Soto R, Gray SJ. Viral expression cassette elements to enhance transgene target specificity and expression in gene therapy. Discov Med. 2015 Jan;19(102):4957.

35 Hagberg B, Aicardi J, Dias K, Ramos O. A progressive syndrome of autism, dementia, ataxia, and loss of purposeful hand use in girls: Rett's syndrome: report of 35 cases. Ann Neurol. 1983 Oct:14(4):471-9.

36 Hagberg B. Clinical manifestations and stages of Rett syndrome. Ment Retard Dev Disabil Res Rev. 2002;8(2):61-5.

37 Julu PO, Kerr AM, Apartopoulos F, Al-Rawas S, Engerström IW, Engerström L, et al. Characterisation of breathing and associated central autonomic dysfunction in the Rett disorder. Arch Dis Child. 2001 Jul;85(1):29-37.

38 Young DJ, Bebbington A, Anderson A, Ravine D, Ellaway C, Kulkarni A, et al. The diagnosis of autism in a female: could it be Rett syndrome? Eur J Pediatr. 2008 Jun;167(6): 661-9.

39 Buchanan CB, Stallworth JL, Scott AE, Glaze DG, Lane JB, Skinner SA, et al. Behavioral profiles in Rett syndrome: data from the natural history study. Brain Dev. 2019 Feb;41(2): 123-34.

40 Cutri-French C, Armstrong D, Saby J, Gorman C, Lane J, Fu C, et al. Comparison of core features in four developmental encephalopathies in the Rett natural history study. Ann Neurol. 2020;88(2):396-406.

41 Neul JL, Lane JB, Lee HS, Geerts S, Barrish JO, Annese F, et al. Developmental delay in Rett syndrome: data from the natural history study. J Neurodev Disord. 2014;6(1):20.

42 Laurvick CL, de Klerk N, Bower C, Christodoulou J, Ravine D, Ellaway C, et al. Rett syndrome in Australia: a review of the epidemiology. J Pediatr. 2006 Mar;148(3):347-52.

43 Akbarian S. The neurobiology of Rett syndrome. Neuroscientist. 2003 Feb;9(1):57-63.

44 Shepherd GM, Katz DM. Synaptic microcircuit dysfunction in genetic models of neurodevelopmental disorders: focus on Mecp2 and Met. Curr Opin Neurobiol. 2011 Dec; 21(6):827-33.

45 Guy J, Gan J, Selfridge J, Cobb S, Bird A. Reversal of neurological defects in a mouse model of Rett syndrome. Science. $2007 \mathrm{Feb}$ 23;315(5815):1143-7.

46 Van Esch H, Bauters M, Ignatius J, Jansen M, Raynaud M, Hollanders K, et al. Duplication of the MECP2 region is a frequent cause of severe mental retardation and progressive neurological symptoms in males. Am J Hum Genet. 2005 Sep;77(3):442-53.

47 Gadalla KK, Bailey ME, Spike RC, Ross PD, Woodard KT, Kalburgi SN, et al. Improved survival and reduced phenotypic severity following AAV9/MECP2 gene transfer to neo- natal and juvenile male Mecp2 knockout mice. Mol Ther. 2013 Jan;21(1):18-30.

48 Gadalla KKE, Vudhironarit T, Hector RD, Sinnett S, Bahey NG, Bailey MES, et al. Development of a novel AAV gene therapy cassette with improved safety features and efficacy in a mouse model of Rett syndrome. Mol Ther Methods Clin Dev. 2017 Jun 16;5:180-90.

49 Sinnett SE, Hector RD, Gadalla KKE, Heindel $\mathrm{C}$, Chen D, Zaric V, et al. Improved MECP2 gene Therapy extends the survival of MeCP2null mice without apparent toxicity after intracisternal delivery. Mol Ther Methods Clin Dev. 2017 Apr 19;5:106-15.

50 Ciaccio C, Fontana L, Milani D, Tabano S, Miozzo M, Esposito S. Fragile X syndrome: a review of clinical and molecular diagnoses. Ital J Pediatr. 2017 Apr 19;43(1):39.

51 Lachiewicz AM, Dawson DV, Spiridigliozzi GA. Physical characteristics of young boys with fragile $\mathrm{X}$ syndrome: reasons for difficulties in making a diagnosis in young males. Am J Med Genet. 2000 Jun 5;92(4):229-36.

52 Musumeci SA, Hagerman RJ, Ferri R, Bosco P, Dalla Bernardina B, Tassinari CA, et al. Epilepsy and EEG findings in males with fragile X syndrome. Epilepsia. 1999 Aug;40(8):10929.

53 Roberts JE, McCary LM, Shinkareva SV, Bailey DB. Infant development in fragile X syndrome: cross-syndrome comparisons. J Autism Dev Disord. 2016 Jun;46(6):2088-99.

54 Arvio M. Fragile-X syndrome-a 20-year follow-up study of male patients. Clin Genet. 2016 Jan;89(1):55-9.

55 Brown WT, Friedman E, Jenkins EC, Brooks J, Wisniewski K, Raguthu S, et al. Association of fragile X syndrome with autism. Lancet. 1982 Jan 9;1(8263):100.

56 Kaufmann WE, Kidd SA, Andrews HF, Budimirovic DB, Esler A, Haas-Givler B, et al. Autism spectrum disorder in fragile $\mathrm{X}$ syndrome: cooccurring conditions and current treatment. Pediatrics. 2017 Jun;139(Suppl 3):S194-206.

57 Alanay Y, Unal F, Turanli G, Alikaşifoğlu M, Alehan D, Akyol U, et al. A multidisciplinary approach to the management of individuals with fragile X syndrome. J Intellect Disabil Res. 2007 Feb;51(Pt 2):151-61.

58 Bailey DB, Raspa M, Olmsted M, Holiday DB. Co-occurring conditions associated with FMR1 gene variations: findings from a national parent survey. Am J Med Genet A. 2008 Aug 15;146A(16):2060-9.

59 Coffee B, Ikeda M, Budimirovic DB, Hjelm LN, Kaufmann WE, Warren ST. Mosaic FMR1 deletion causes fragile $X$ syndrome and can lead to molecular misdiagnosis: a case report and review of the literature. Am J Med Genet A. 2008;146A(10):1358-67.

60 De Boulle K, Verkerk AJMH, Reyniers E, Vits L, Hendrickx J, Van Roy B, et al. A point mutation in the FMR-1 gene associated with fragile X mental retardation. Nat Genet. 1993;3: $31-5$

61 Crawford DC, Meadows KL, Newman JL, Taft LF, Scott E, Leslie M, et al. Prevalence of the fragile $\mathrm{X}$ syndrome in African-Americans. Am J Med Genet. 2002;110(3):226-33.

62 Sherman SL, Kidd SA, Riley C, Berry-Kravis E, Andrews HF, Miller RM, et al. FORWARD: a registry and longitudinal clinical database to study fragile X syndrome. Pediatrics. 2017 Jun;139(Suppl 3):S183-93.

63 Kong HE, Zhao J, Xu S, Jin P, Jin Y. Fragile Xassociated tremor/ataxia syndrome: from molecular pathogenesis to development of therapeutics. Front Cell Neurosci. 2017;11:128.

64 Pieretti M, Zhang FP, Fu YH, Warren ST, Oostra BA, Caskey CT, et al. Absence of expression of the FMR-1 gene in fragile $\mathrm{X}$ syndrome. Cell. 1991 Aug 23;66(4):817-22.

65 Feng Y, Zhang F, Lokey LK, Chastain JL, Lakkis L, Eberhart D, et al. Translational suppression by trinucleotide repeat expansion at FMR1. Science. 1995 May 5;268(5211):731-4.

66 Colak D, Zaninovic N, Cohen MS, Rosenwaks Z, Yang WY, Gerhardt J, et al. Promoterbound trinucleotide repeat mRNA drives epigenetic silencing in fragile $\mathrm{X}$ syndrome. Science. 2014 Feb 28;343(6174):1002-5.

67 Kim K, Hessl D, Randol JL, Espinal GM, Schneider A, Protic D, et al. Association between IQ and FMR1 protein (FMRP) across the spectrum of CGG repeat expansions. PLoS One. 2019;14(12):e0226811.

68 Doll CA, Broadie K. Neuron class-specific requirements for fragile $\mathrm{X}$ mental retardation protein in critical period development of calcium signaling in learning and memory circuitry. Neurobiol Dis. 2016 May 1;89:76-87.

69 Siegel JJ, Chitwood RA, Ding JM, Payne C, Taylor W, Gray R, et al. Prefrontal cortex dysfunction in fragile $\mathrm{X}$ mice depends on the continued absence of fragile $\mathrm{X}$ mental retardation protein in the adult brain. J Neurosci. 2017 Aug 2;37(31):7305-17.

70 Gross C, Hoffmann A, Bassell GJ, Berry-Kravis $\mathrm{EM}$. Therapeutic strategies in fragile $\mathrm{X}$ syndrome: from bench to bedside and back. Neurotherapeutics. 2015 Jul;12(3):584-608.

71 Mullard A. Fragile X disappointments upset autism ambitions. Nat Rev Drug Discov. 2015 Mar;14(3):151-3.

72 Fmr1 knockout mice: a model to study fragile $\mathrm{X}$ mental retardation. The Dutch-Belgian fragile X consortium. Cell. 1994 Jul 15;78(1): 23-33.

73 Irwin SA, Patel B, Idupulapati M, Harris JB, Crisostomo RA, Larsen BP, et al. Abnormal dendritic spine characteristics in the temporal and visual cortices of patients with fragile-X syndrome: a quantitative examination. Am J Med Genet. 2001 Jan 15;98(2):161-7.

74 Irwin SA, Idupulapati M, Gilbert ME, Harris JB, Chakravarti AB, Rogers EJ, et al. Dendritic spine and dendritic field characteristics of layer $\mathrm{V}$ pyramidal neurons in the visual cortex of fragile-X knockout mice. Am J Med Genet. 2002 Aug 1;111(2):140-6.

75 Scharf SH, Jaeschke G, Wettstein JG, Lindemann L. Metabotropic glutamate receptor 5 as drug target for fragile $\mathrm{X}$ syndrome. Curr Opin Pharmacol. 2015 Feb;20:124-34. 
76 Gholizadeh S, Arsenault J, Xuan IC, Pacey LK, Hampson DR. Reduced phenotypic severity following adeno-associated virus-mediated Fmrl gene delivery in fragile $\mathrm{X}$ mice. Neuropsychopharmacology. 2014 Dec;39(13): 3100-11.

77 Arsenault J, Gholizadeh S, Niibori Y, Pacey LK, Halder SK, Koxhioni E, et al. FMRP expression levels in mouse central nervous system neurons determine behavioral phenotype. Hum Gene Ther. 2016;27(12):982-96.

78 Hampson DR, Hooper AWM, Niibori Y. The application of adeno-associated viral vector gene therapy to the treatment of fragile $\mathrm{X}$ syndrome. Brain Sci. 2019 Feb 2;9(2).

79 Buntinx IM, Hennekam RC, Brouwer OF, Stroink H, Beuten J, Mangelschots K, et al. Clinical profile of Angelman syndrome at different ages. Am J Med Genet. 1995;56(2):17683.

80 Galván-Manso $\mathrm{M}$, Campistol J, Conill J, Sanmartí FX. Analysis of the characteristics of epilepsy in 37 patients with the molecular diagnosis of Angelman syndrome. Epileptic Disord. 2005 Mar;7(1):19-25.

81 Harting I, Seitz A, Rating D, Sartor K, Zschocke J, Janssen B, et al. Abnormal myelination in Angelman syndrome. Eur J Paediatr Neurol. 2009 May;13(3):271-6.

82 Williams CA. The behavioral phenotype of the Angelman syndrome. Am J Med Genet. 2010;154C(4):432-7.

83 Larson AM, Shinnick JE, Shaaya EA, Thiele EA, Thibert RL. Angelman syndrome in adulthood. Am J Med Genet A. 2015 Feb; $167 \mathrm{~A}(2): 331-44$

84 Bird LM. Angelman syndrome: review of clinical and molecular aspects. Appl Clin Genet. 2014;7:93-104.

85 Reik W, Walter J. Genomic imprinting: parental influence on the genome. Nat Rev Genet. $2001 \mathrm{Jan} ; 2(1): 21-32$.

86 Rougeulle C, Glatt H, Lalande M. The Angelman syndrome candidate gene, UBE3A/E6AP, is imprinted in brain. Nat Genet. 1997 Sep;17(1):14-5.

87 Nazlican H, Zeschnigk M, Claussen U, Michel S, Boehringer S, Gillessen-Kaesbach G, et al. Somatic mosaicism in patients with Angelman syndrome and an imprinting defect. Hum Mol Genet. 2004 Nov 1;13(21):254755.

88 Keute M, Miller MT, Krishnan ML, Sadhwani A, Chamberlain S, Thibert RL, et al. Angelman syndrome genotypes manifest varying degrees of clinical severity and developmental impairment. Mol Psychiatry. 2020 Aug 13.

89 Jiang YH, Armstrong D, Albrecht U, Atkins CM, Noebels JL, Eichele G, et al. Mutation of the Angelman ubiquitin ligase in mice causes increased cytoplasmic $p 53$ and deficits of contextual learning and long-term potentiation. Neuron. 1998 Oct 1;21(4):799-811.
90 Rotaru DC, Mientjes EJ, Elgersma Y. Angelman syndrome: from mouse models to therapy. Neuroscience. 2020 01;445:172-89.

91 Daily JL, Nash K, Jinwal U, Golde T, Rogers J, Peters MM, et al. Adeno-associated virus-mediated rescue of the cognitive defects in a mouse model for Angelman syndrome. PLoS One. 2011;6(12):e27221.

92 Silva-Santos S, van Woerden GM, Bruinsma CF, Mientjes E, Jolfaei MA, Distel B, et al. Ube3a reinstatement identifies distinct developmental windows in a murine Angelman syndrome model. J Clin Invest. 2015 May 1;125(5):2069-76.

93 Buiting K, Williams C, Horsthemke B. Angelman syndrome-insights into a rare neurogenetic disorder. Nat Rev Neurol. 2016; 12(10):584-93.

94 Huang HS, Allen JA, Mabb AM, King IF, Miriyala J, Taylor-Blake B, et al. Topoisomerase inhibitors unsilence the dormant allele of Ube3a in neurons. Nature. 2012 Jan; 481(7380):185-9.

95 Meng L, Person RE, Huang W, Zhu PJ, Costa-Mattioli M, Beaudet AL. Truncation of Ube3a-ATS unsilences paternal Ube3a and ameliorates behavioral defects in the Angelman syndrome mouse model. PLoS Genet. 2013 Dec 26;9(12):e1004039.

96 Meng L, Ward AJ, Chun S, Bennett CF, Beaudet AL, Rigo F. Towards a therapy for Angelman syndrome by targeting a long non-coding RNA. Nature. 2015 Feb 19; 518(7539):409-12.

97 GeneTX Biotherapeutics, LLC. A phase 1/2 open-label, multiple-dose, dose-escalating clinical trial of the safety and tolerability of GTX-102 in pediatric patients with Angelman syndrome (AS) [Internet]. clinicaltrials.gov; 2020 Aug [cited 2021 Jan 21]. Report No. NCT04259281.

98 Wolter JM, Mao H, Fragola G, Simon JM, Krantz JL, Bazick HO, et al. Cas9 gene therapy for Angelman syndrome traps Ube3aATS long non-coding RNA. Nature. 2020 Nov;587(7833):281-4.

99 Elgersma Y. Neurodevelopmental disease: a molecular tightrope. Nature. 2015 Oct; 526(7571):50-1.

100 Thevenon J, Milh M, Feillet F, St-Onge J, Duffourd Y, Jugé C, et al. Mutations in SLC13A5 cause autosomal-recessive epileptic encephalopathy with seizure onset in the first days of life. Am J Hum Genet. 2014 Jul 3;95(1):113-20.

101 Hardies K, de Kovel CG, Weckhuysen S, Asselbergh B, Geuens T, Deconinck T, et al. Recessive mutations in SLC13A5 result in a loss of citrate transport and cause neonatal epilepsy, developmental delay and teeth hypoplasia. Brain. 2015 Nov;138(Pt 11):323850.

102 Klotz J, Porter BE, Colas C, Schlessinger A, Pajor AM. Mutations in the $\mathrm{Na}(+) /$ citrate cotransporter $\mathrm{NaCT}$ (SLC13A5) in pediatric patients with epilepsy and developmental delay. Mol Med. 2016;22:22.
103 Inoue K, Zhuang L, Maddox DM, Smith SB, Ganapathy V. Human sodium-coupled citrate transporter, the orthologue of Drosophila Indy, as a novel target for lithium action. Biochem J. 2003 Aug 15;374(Pt 1):216.

104 Bainbridge MN, Cooney E, Miller M, Kennedy AD, Wulff JE, Donti T, et al. Analyses of SLC13A5-epilepsy patients reveal perturbations of TCA cycle. Mol Genet Metab. 2017;121(4):314-9.

105 Selch S, Chafai A, Sticht H, Birkenfeld AL, Fromm MF, König J. Analysis of naturally occurring mutations in the human uptake transporter $\mathrm{NaCT}$ important for bone and brain development and energy metabolism. Sci Rep. 2018 27;8(1):11330.

106 Iacobazzi V, Infantino V. Citrate-new functions for an old metabolite. Biol Chem. 2014 Apr;395(4):387-99.

107 Bhutia YD, Kopel JJ, Lawrence JJ, Neugebauer V, Ganapathy V. Plasma membrane $\mathrm{Na}+$-coupled citrate transporter (SLC13A5) and neonatal epileptic encephalopathy. Molecules. 2017 Feb 28;22(3):378.

108 Alhakeem A, Alshibani F, Tabarki B. Extending the use of stiripentol to SLC13A5related epileptic encephalopathy. Brain Dev. 2018 Oct;40(9):827-9.

109 Kann O. The interneuron energy hypothesis: implications for brain disease. Neurobiol Dis. 2016 Jun;90:75-85.

110 Matricardi S, De Liso P, Freri E, Costa P, Castellotti B, Magri S, et al. Neonatal developmental and epileptic encephalopathy due to autosomal recessive variants in SLC13A5 gene. Epilepsia. 2020 Oct 16.

111 Yang QZ, Spelbrink EM, Nye KL, Hsu ER, Porter BE. Epilepsy and EEG phenotype of SLC13A5 citrate transporter disorder. Child Neurol Open. 2020 Jan-Dec Dec; 7: $2329048 X 20931361$.

112 Henke C, Töllner K, van Dijk RM, Miljanovic N, Cordes T, Twele F, et al. Disruption of the sodium-dependent citrate transporter SLC13A5 in mice causes alterations in brain citrate levels and neuronal network excitability in the hippocampus. Neurobiol Dis. 2020;143:105018.

113 Weeke LC, Brilstra E, Braun KP, ZonneveldHuijssoon E, Salomons GS, Koeleman BP, et al. Punctate white matter lesions in full-term infants with neonatal seizures associated with SLC13A5 mutations. Eur J Paediatr Neurol. 2017 Mar;21(2):396-403.

114 Kopel JJ, Bhutia YD, Ramachandran S, Lawrence J, Neugebauer V, Ganapathy V. Tooth hypoplasia for differential diagnosis of childhood epilepsy associated with SLC13A5 mutations. 2007.

115 Arvio M, Lähdetie J. Adult phenotype of the homozygous missense mutation c.655G $>$ A, p.Gly219Arg in SLC13A5: a case report. Am J Med Genet A. 2020;182(11):2671-4. 
116 Carvill GL, McMahon JM, Schneider A, Zemel M, Myers CT, Saykally J, et al. Mutations in the GABA transporter SLC6A1 cause epilepsy with myoclonic-atonic seizures. Am J Hum Genet. 2015 May 7;96(5): 808-15.

117 Rauch A, Wieczorek D, Graf E, Wieland T, Endele S, Schwarzmayr T, et al. Range of genetic mutations associated with severe nonsyndromic sporadic intellectual disability: an exome sequencing study. Lancet. 2012 Nov 10;380(9854):1674-82.

118 Goodspeed K, Pérez-Palma E, Iqbal S, Cooper D, Scimemi A, Johannesen KM, et al. Current knowledge of SLC6A1-related neurodevelopmental disorders. Brain Commun. $2020 \mathrm{~J} ; 2$ (2):fcaa170.

119 Johannesen KM, Gardella E, Linnankivi T, Courage C, de Saint Martin A, Lehesjoki AE, et al. Defining the phenotypic spectrum of SLC6A1 mutations. Epilepsia. 2018;59(2): 389-402.

120 Scimemi A. Structure, function, and plasticity of GABA transporters. Front Cell Neurosci. 2014;8:161.

121 Gamazon ER, Segrè AV, van de Bunt M, Wen X, Xi HS, Hormozdiari F, et al. Using an atlas of gene regulation across 44 human tissues to inform complex disease- and traitassociated variation. Nat Genet. 2018;50(7): 956-67.

122 Minelli A, Brecha NC, Karschin C, DeBiasi S, Conti F. GAT-1, a high-affinity GABA plasma membrane transporter, is localized to neurons and astroglia in the cerebral cortex. J Neurosci. 1995 Nov;15(11):773446.

$123 \mathrm{Wu}$ C, Sun D. GABA receptors in brain development, function, and injury. Metab Brain Dis. 2015 Apr;30(2):367-79.

124 Kilb W. Development of the GABAergic system from birth to adolescence. Neuroscientist. 2012 Dec;18(6):613-30.

125 Chiu CS, Brickley S, Jensen K, Southwell A, Mckinney S, Cull-Candy S, et al. GABA transporter deficiency causes tremor, ataxia, nervousness, and increased GABA-induced tonic conductance in cerebellum. J Neurosci. 2005 Mar 23;25(12):3234-45.

126 Cope DW, Di Giovanni G, Fyson SJ, Orbán G, Errington AC, Lorincz ML, et al. Enhanced tonic GABAA inhibition in typical absence epilepsy. Nat Med. 2009 Dec;15(12): 1392-8.

127 Chamberlain K, Riyad JM, Weber T. Expressing transgenes that exceed the packaging capacity of adeno-associated virus capsids. Hum Gene Ther Methods. 2016 Feb; 27(1):1-12

128 Jensen K, Chiu CS, Sokolova I, Lester HA, Mody I. GABA transporter-1 (GAT1)-deficient mice: differential tonic activation of GABAA versus $G A B A B$ receptors in the hippocampus. J Neurophysiol. 2003 Oct; 90(4):2690-701.

129 Schousboe A, Madsen KK, Barker-Haliski ML, White HS. The GABA synapse as a target for antiepileptic drugs: a historical over- view focused on GABA transporters. Neurochem Res. 2014 Oct;39(10):1980-7.

130 Bird LM, Tan WH, Bacino CA, Peters SU, Skinner SA, Anselm I, et al. A therapeutic trial of pro-methylation dietary supplements in Angelman syndrome. Am J Med Genet A. 2011 Dec;155A(12):2956-63.

131 van Woerden GM, Harris KD, Hojjati MR, Gustin RM, Qiu S, de Avila Freire R, et al. Rescue of neurological deficits in a mouse model for Angelman syndrome by reduction of alphaCaMKII inhibitory phosphorylation. Nat Neurosci. 2007 Mar;10(3):280-2.

132 Yoon HM, Jo Y, Shim WH, Lee JS, Ko TS, Koo JH, et al. Disrupted functional and structural connectivity in Angelman syndrome. AJNR Am J Neuroradiol. 2020; 41(5):889-97.

133 Key AP, Jones D, Peters S, Dold C. Feasibility of using auditory event-related potentials to investigate learning and memory in nonverbal individuals with Angelman syndrome. Brain Cogn. 2018;128:73-9.

134 Sidorov MS, Deck GM, Dolatshahi M, Thibert RL, Bird LM, Chu CJ, et al. Delta rhythmicity is a reliable EEG biomarker in Angelman syndrome: a parallel mouse and human analysis. J Neurodev Disord. 2017;9:17.

135 Sidorov MS, Deck GM, Dolatshahi M, Thibert RL, Bird LM, Chu CJ, et al. Erratum to: delta rhythmicity is a reliable EEG biomarker in Angelman syndrome: a parallel mouse and human analysis. J Neurodev Disord. 2017;9:30. 